\title{
Aspect-controlled spatial and temporal soil moisture patterns across three different latitudes
}

\author{
A. Srivastava, O. Yetemen, N. Kumari and P. M. Saco \\ School of Engineering, Faculty of Engineering and Built Environment, The University of Newcastle, \\ Callaghan, NSW 2308, Australia. \\ Email: Ankur.Srivastava@uon.edu.au
}

\begin{abstract}
Soil moisture in semi-arid areas plays a critical role as it regulates numerous ecohydrologic processes in land surface hydrology, subsurface hydrology, and vegetation dynamics. Studies on soil moisture distribution and dynamics currently rely on data obtained using three types of approaches: in situ (generally point-scale) measurements, remotely sensed observations, and modelling approaches. The spatial variability of soil moisture plays a vital role in the estimation of land surface fluxes (evapotranspiration (ET) and runoff) due to the non-linear relationship between soil moisture and the associated physical processes. Understanding this variability is essential for the optimal management of water resources and ecosystem sustainability. Although a considerable amount of work has been done on the subject, the ability to understand and characterize the mechanisms that determine the distribution patterns of soil water content still remains a challenge at the centre of hydrological research, especially for ungauged catchments. It is necessary to understand the spatial variability of soil moisture and its influencing factors, which will provide a basis to improve our understanding of hydrological, biogeochemical processes, and lateral and subsurface flow processes.
\end{abstract}

The effects of several factors that control soil moisture variability (SMV) in semi-arid landscapes (microclimate, vegetation, topography, soil depth, soil texture, etc.) have been documented in previous work. However, the control of latitude on SMV under different environmental conditions still remains poorly understood. Latitude significantly affects the availability of water and energy as the global distribution of solar radiation varies from the equator to higher latitudes. Latitude has a dominant control on the availability of water because of the varying amount of solar radiation on north-facing slopes (NFS) and south-facing slopes (SFS), which influences soil moisture variations. This study focusses on evaluating and comparing the effect of latitude on SMV, and its control on soil moisture patterns. To this end, we use a modelling framework to capture the joint effects of aspect and latitude on SMV.

We used the Bucket Grassland Model (BGM), equipped with a vegetation dynamics component, to analyse soil moisture patterns and variability at various latitudes $\left(45^{\circ} \mathrm{N}, 34^{\circ} \mathrm{N}\right.$, and $\left.15^{\circ} \mathrm{N}\right)$. The main objective of this study is to investigate changes in soil moisture patterns at various latitudes and differences in SMV on the different aspects for a synthetic domain. We conducted different simulations as a sensitivity analysis (at various latitudes) using BGM to study the effect of aspect-related soil moisture variations in a semi-arid landscape. The latitudinal patterns of modeled soil moisture are analysed, and distinct variations are identified in the SMV.

The results show that water stress varies with aspect and are affected by latitude, which in turn affect the SMV. Further, they show that SMV increases moving towards higher latitudes. Also, aspect-related soil moisture differences are enhanced at higher latitudes. Therefore, it is not possible to characterize soil moisture variations or model surface hydrological processes at the catchment scale, without explicitly accounting for aspect, particularly in ecosystems where the aspect has a dominant effect.

Keywords: Soil moisture, aspect, latitude, vegetation dynamics 


\section{INTRODUCTION}

Soil moisture is a key variable in various environmental processes at both regional and global scales. Its accurate estimation is needed for hydrologic, climatic, and agricultural applications, such as water management and irrigation scheduling, weather and climatic prediction, drought monitoring, and flood forecasting (Western et al., 2004; Famiglietti et al., 2008). Consequently the causes and effects of its highly variable nature in space and time continue to draw significant attention within the research community. Understanding the spatial variability of soil moisture is critical for improving the performance of hydrological and atmospheric models. It is also intrinsically related to the distribution of vegetation patches in semiarid regions (Saco and Morenode las Heras, 2013; Saco et al., 2018). Current methods for estimating and measuring soil moisture can be broadly divided into three main groups: 1) in situ (generally point-scale) measurements; 2) remote sensing observations, and 3) numerical modelling. Given the limited availability of in situ measurements and its high spatio-temporal variability at different scales (Famiglietti et al., 2008; Penna et al., 2013), the estimation of soil moisture is a challenging task. There have been various studies aiming at understanding the spatial characteristics of soil moisture, as well as correlation analyses between spatial patterns of soil moisture (Famiglietti et al., 2008; Ivanov et al., 2010; Fatichi et al., 2015). These studies have demonstrated that the coefficient of variation of soil moisture $(\mathrm{CV})$ is inversely related to the mean spatial soil moisture content, arguing that catchments tend to display larger variability in the spatial distribution of soil moisture during periods of intermediate soil moisture content rather than for very wet or dry periods (Western et al., 2004; Choi et al., 2007; Famiglietti et al., 2008; Brocca et al., 2012).

Previous work has looked at the effect of several factors, including vegetation, climate, soil hydraulic properties, and topography on soil moisture variability (Martinez et al., 2008; Famiglietti et al., 2008; Chen et al., 2014; Fatichi et al., 2015; Rossi et al., 2018). However, the role of latitude and aspect in soil moisture variability (SMV) has only been addressed by very few studies (Reid 1973; Bass et al., 2016). The annual mean extra-terrestrial radiation is maximum at the equator $\left(\sim 400 \mathrm{~W} / \mathrm{m}^{2}\right)$, and achieves minimum values at the poles $\left(\sim 300 \mathrm{~W} / \mathrm{m}^{2}\right)$. This variability affects the seasonal variation in insolation on north-facing slopes (NFS) and south-facing slopes (SFS) differently for varying latitudes (Yetemen et al. 2015a). Insolation varies as a function of hillslope gradients and aspects, and the difference in insolation on opposing hillslopes is amplified as a function of latitude (Yetemen et al., 2015b; Zhou et al., 2013). This discrepancy is more pronounced in midlatitudes which in turn gives the least variation at this range, showing that soil moisture is crucial role in semi-arid ecosystems.

In this study, we investigate the role of aspect and latitude on soil moisture variability using a modelling framework (BGM, Istanbulluoglu et al., 2012). BGM (Bucket Grassland Model) is equipped with a spatiallydistributed solar-radiation component that couples vegetation dynamics and surface hydrology. We investigate the differences in simulated soil moisture patterns over a synthetic landscape domain. To this end, we designed a set of BGM simulations driven by spatially variable solar radiation to investigate the spatial and temporal soil moisture patterns at three different latitudes $\left(15^{\circ} \mathrm{N}, 34^{\circ} \mathrm{N}\right.$, and $\left.45^{\circ} \mathrm{N}\right)$. There are two main assumptions in our simulations. We assume a uniform precipitation, which in real conditions may vary spatially throughout the topography. We also assume that the soil properties and soil depth are uniform throughout the spatial domain, which may differ from real conditions.

\section{STUDY SITE DESCRIPTION}

The model (BGM) utilized in this study has been previously calibrated and validated in Sevilleta National Wildlife Refuge (SNWR) in central New Mexico by using runoff, soil moisture, actual evapotranspiration, and MODIS leaf area index (LAI) (Yetemen et al., 2015a). The SNWR comes under semi-arid ecosystem with an annual rainfall of $250 \mathrm{~mm}$ where almost $50 \%$ of the rainfall occurs during North American Monsoon (NAM) from July to September. The soil texture is loamy sand with vegetation of grass having a root depth of $30 \mathrm{~cm}$. The model is calibrated at a daily time scale with Nash-Sutcliffe efficiency (NSE) of 0.76 as described in Yetemen et al. (2015a). We have run the simulations on the synthetic domain of $900 \mathrm{~m}$ by $900 \mathrm{~m}$ having $20 \mathrm{~m}$ spacing between each node with elevation ranging between 0 and $67 \mathrm{~m}$, and drainage is only permitted through a single side of the domain as shown in Figure 1.

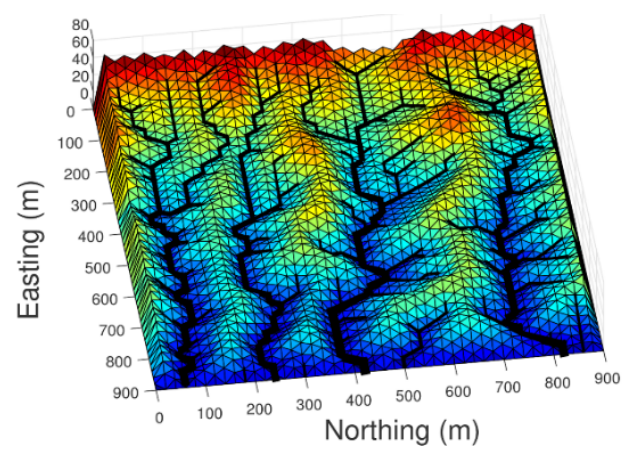

Figure 1. The synthetic domain used in BGM to analyse the SMV. 


\section{METHODOLOGY}

\subsection{BGM Model Description}

BGM is an ecohydrological model that simulates the dynamics of vegetation for a single-species. In this model, the root zone soil moisture is vertically averaged using a single bucket approach. The biomass is distributed in two forms, namely above- and below-ground biomass to track the transpiration process. Biomass levels in the aboveground pools define both dead- and live-vegetation fraction and the remaining is the bare soil. The model also simulates the decay of live biomass and tracks it as dead biomass within these pools. During the interstorm period, evapotranspiration, vegetation growth, and decay are computed, whereas soil moisture content is computed before the arrival of the next storm.

Here we use the BGM model to understand the effect of aspect and latitude on the variability of soil moisture. To simulate the soil moisture dynamics, the BGM uses volume-balance equation:

$\phi R_{z} \frac{d s}{d t}=I-L(s)-E T_{a}(s)$

where changes in the available soil moisture at the given time $\left(\frac{d s}{d t}\right)$ are computed by the equation (1) in which the maximum available soil moisture is $\phi R_{z}, s[-]$ is the soil saturation within the root zone, $t[\mathrm{~T}]$ is time, $\phi$ [-] is the porosity of the soil, and $R_{z}[\mathrm{~L}]$ is the effective rooting depth, $I\left[\mathrm{LT}^{-1}\right]$ is root zone infiltration, $L\left[\mathrm{LT}^{-1}\right]$ is leakage rate from the entire root zone. Actual evapotranspiration, $E T_{a}\left[\mathrm{LT}^{-1}\right]$, is scaled PET (potential evapotranspiration calculated based on a Penman-Monteith approach for a flat surface at any latitude) scaled with available root zone soil moisture as described in Laio et al. (2001) and Yetemen et al. (2015a). Leakage out of the root zone is set equal to the unsaturated hydraulic conductivity, which is described with an exponential function (Laio et al., 2001). For a sloped surface, $P E T$ is scaled based on a ratio of incoming solar radiation for a sloped surface to the one on a flat surface at the same time.

\subsection{Simulation Analysis}

The model was used to simulate the dynamics of soil moisture over the entire synthetic domain and for three different latitudes over a time period of 100 years (using stochastically generated rainfall data for the study region). The spatial and temporal variability were analysed using two different averaging approaches as shown in Figure 2 and discussed below. The schematic shown in Figure 2a represents the simulated soil moisture data over the entire domain (including 1936 pixels) and the entire 100-year time period (4507 time steps). In order to analyse the variability of soil moisture over time, we computed a mean value of soil moisture from all pixels in the synthetic domain, and we obtained a value for each time step (as illustrated in Figure 2b). Hereafter, we refer to this value as mean spatial soil moisture, $\langle\theta\rangle$. The mean spatial variance was also computed in order to estimate the coefficient of variation, $(\mathrm{CV})$. In order to capture the variability of soil moisture in space (including areas with different aspects), we computed for each of the pixel the mean value of soil moisture over the entire period (Figure 2c). We will refer to this value as $\bar{\theta}$.

The black dots shown in Figure 2d display the values of $C V$ versus $\langle\theta\rangle$ (for a latitude of $34^{\circ}$ ). The figure also shows the results obtained from binning the values, which leads to a simpler plot, more easily comparable to previous results presented in the literature.

The following sections analyse the variability of mean spatial soil moisture (by looking at changes in the $C V-\langle\theta\rangle$ binned plots) for different latitudes, and the effect of aspect on the variability of $\bar{\theta}$ also for different latitudes $\left(15^{\circ} \mathrm{N}, 34^{\circ} \mathrm{N}\right.$, and $\left.45^{\circ} \mathrm{N}\right)$. 


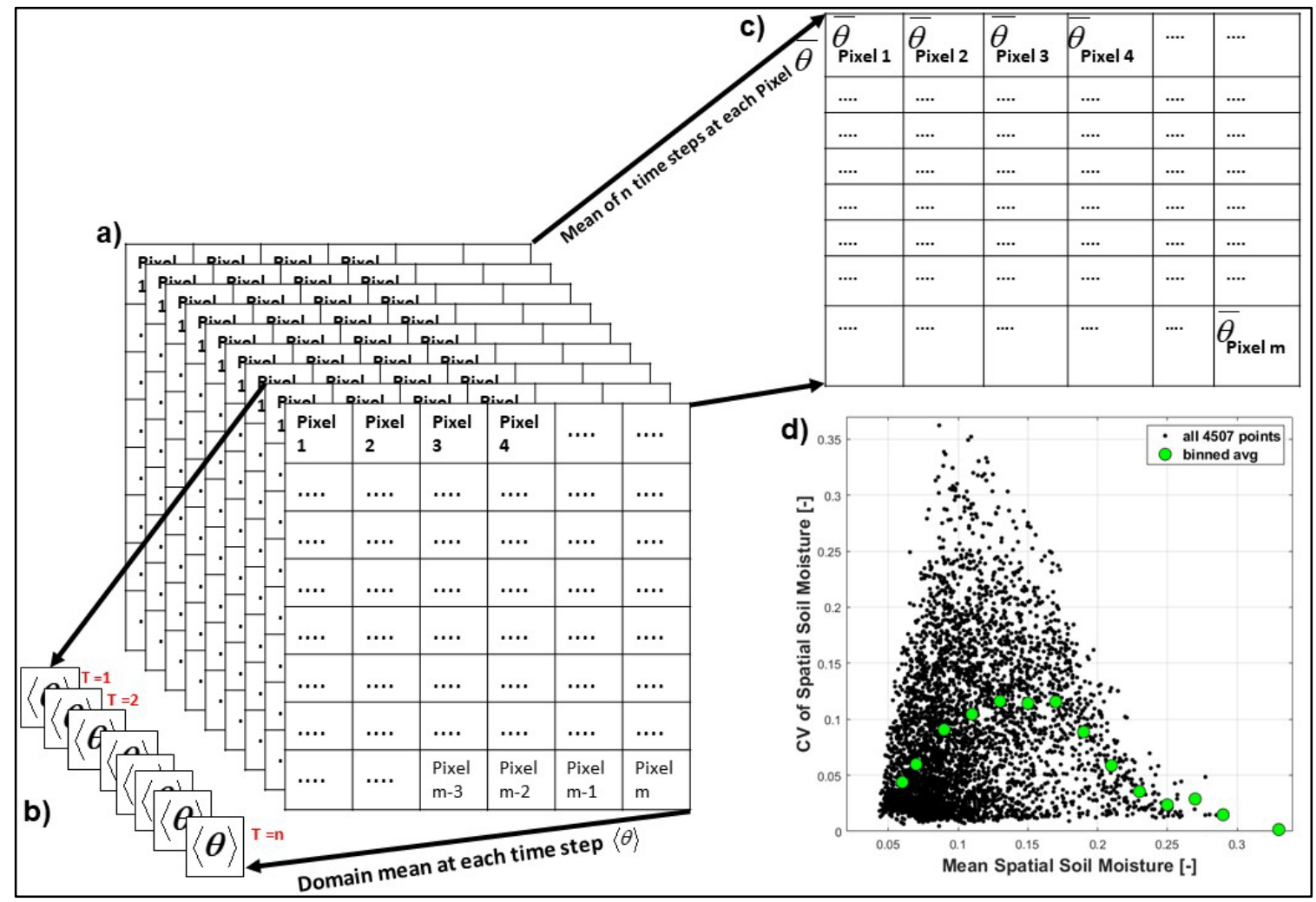

Figure 2. Schematic showing the conceptual framework for carrying out mean spatio-temporal soil moisture analysis: (a) modelled soil moisture values for $m$ (1936) pixels and $n$ (4507) time steps for the entire domain; (b) distribution of the mean spatial soil moisture $\langle\theta\rangle$ over $n$ time steps; (c) distribution of the mean temporal soil moisture $\bar{\theta}$ over $m$ pixels. (d) $C V-\langle\theta\rangle$ for all pixels in the domain (black dots) and binned averaged values (green dots) obtained from soil moisture simulations at the reference latitude $\left(34^{\circ} \mathrm{N}\right)$.

\section{RESULTS AND DISCUSSION}

\subsection{Spatial soil moisture variability}

Figure 3 shows the results of SMV obtained from the spatially averaged and binned values $C V-\langle\theta\rangle$ (as displayed in Figure $2 \mathrm{~d}$ and explained in Section 3 ) for three latitudes selected $\left(15^{\circ} \mathrm{N}, 34^{\circ} \mathrm{N}\right.$, and $\left.45^{\circ} \mathrm{N}\right)$. The plot displays a convex shape for the $C V-\langle\theta\rangle$ relation with a maximum spatial variance in $\langle\theta\rangle$ found for mid-values of mean soil moisture content and low values for the drier and wetter soil moisture states (wet and dry periods) which is in agreement with previous results from modelling and field studies (Famiglietti et al., 2008; Fatichi et al., 2015; Yetemen et al., 2015a). It shows that SMV is much higher for simulations corresponding to the $45^{\circ} \mathrm{N}$ latitude that display $C V$ values in the range $(0-0.19)$. As seen in this plot, SMV substantially decreases towards lower latitudes, showing that the $15^{\circ} \mathrm{N}$ latitude displays the least variability with $C V$ in the range (0-0.06).

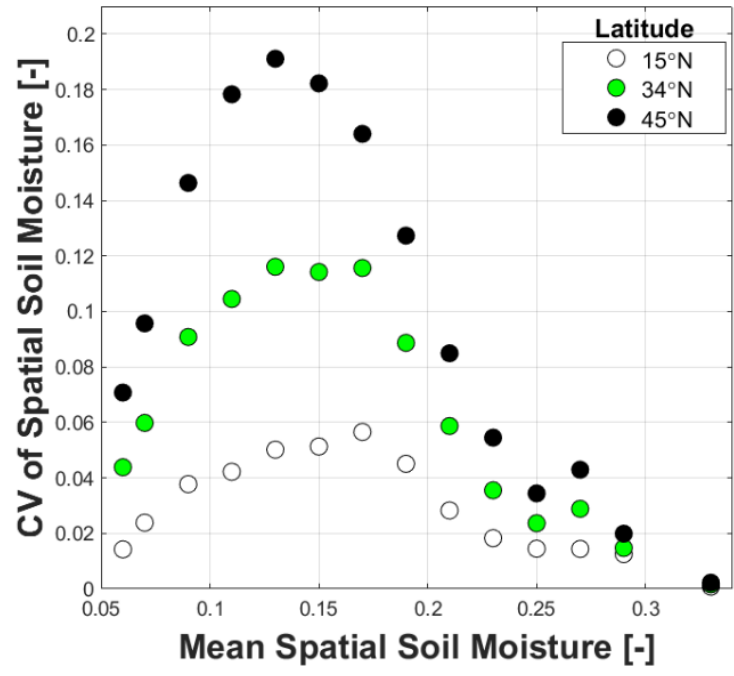

Figure 3. The coefficient of spatial variation of soil moisture content, $C V$ plotted as a function of its spatial mean soil moisture $\langle\theta\rangle$ over the entire domain for three different latitudes. 
This pattern can be attributed to the distribution of solar insolation as a function of latitude; global insolation decreases with increasing latitude when we head from the equator towards higher latitudes (Yetemen et al., 2015a). In addition, in the Northern Hemisphere, especially in fall and winter, the difference in magnitude of incoming solar radiation on the NFS and the SFS becomes larger, which increases the magnitude of overall SMV towards higher latitudes (Gutiérrez-Jurado et al., 2013; Yetemen et al., 2015b).

\subsection{Effect of aspect on temporal soil moisture patterns}

Figure 4 shows the results of $\bar{\theta}$, which are plotted as a function of drainage area for three latitudes $\left(15^{\circ} \mathrm{N}\right.$, $34^{\circ} \mathrm{N}$, and $45^{\circ} \mathrm{N}$ ). In order to explore the effect of aspect, the pixels are classified as North $=315^{\circ}-360^{\circ}$ and $0^{\circ}$ $45^{\circ}$; East $=45^{\circ}-135^{\circ}$; South $=135^{\circ}-225^{\circ}$; and West $=225^{\circ}-315^{\circ}$. It is interesting to note that, as here we are capturing the long-term temporal mean of soil moisture content, the $\bar{\theta}$ values $(0.089-0.148)$ are lower than the $\langle\theta\rangle$ values reported in Figure 3 that spanned the range $(0.060-0.330)$. As mentioned before, $\langle\theta\rangle$ represents the spatial average over the entire domain at each time-step and shows that the variability induced by seasonal differences in rainfall inputs, $P E T$ demand and $E T_{a}$ over time is larger than that induced by spatial soil moisture distribution (at least over this relatively small domain). The figure shows that a decreasing soil moisture trend is observed for the NFS as we move towards the outlet (increasing drainage areas and reducing hillslope gradients). The reversed trend, that is increasing mean soil mositure content, is observed for the SFS as drainage area increases. These trends are produced by the effect of slope angle. The upper hillslope areas, are usually steeper, which affects insolation. Steep NFS have lower inslation than flat slopes, while steep SFS have higher insolation than flat ones. This explains the trends as areas with higher insolation have more evaporation and smaller soil moisture. As contributing area increases, NFS and SFS tend to be flat (similar exposure to solar radiation for both NFS and SFS), and this is why the soil moisture content for all pixels converges to the same value. The role of aspect is insignificant on the east- and west-facing slopes, as they do not have any variation in the range of $\bar{\theta}$; they all have values close to that for a flat surface. There is a slight increase in the soil moisture by increasing area for east- and west-facing slopes due to enhancement of lateral flows with higher contributing areas.

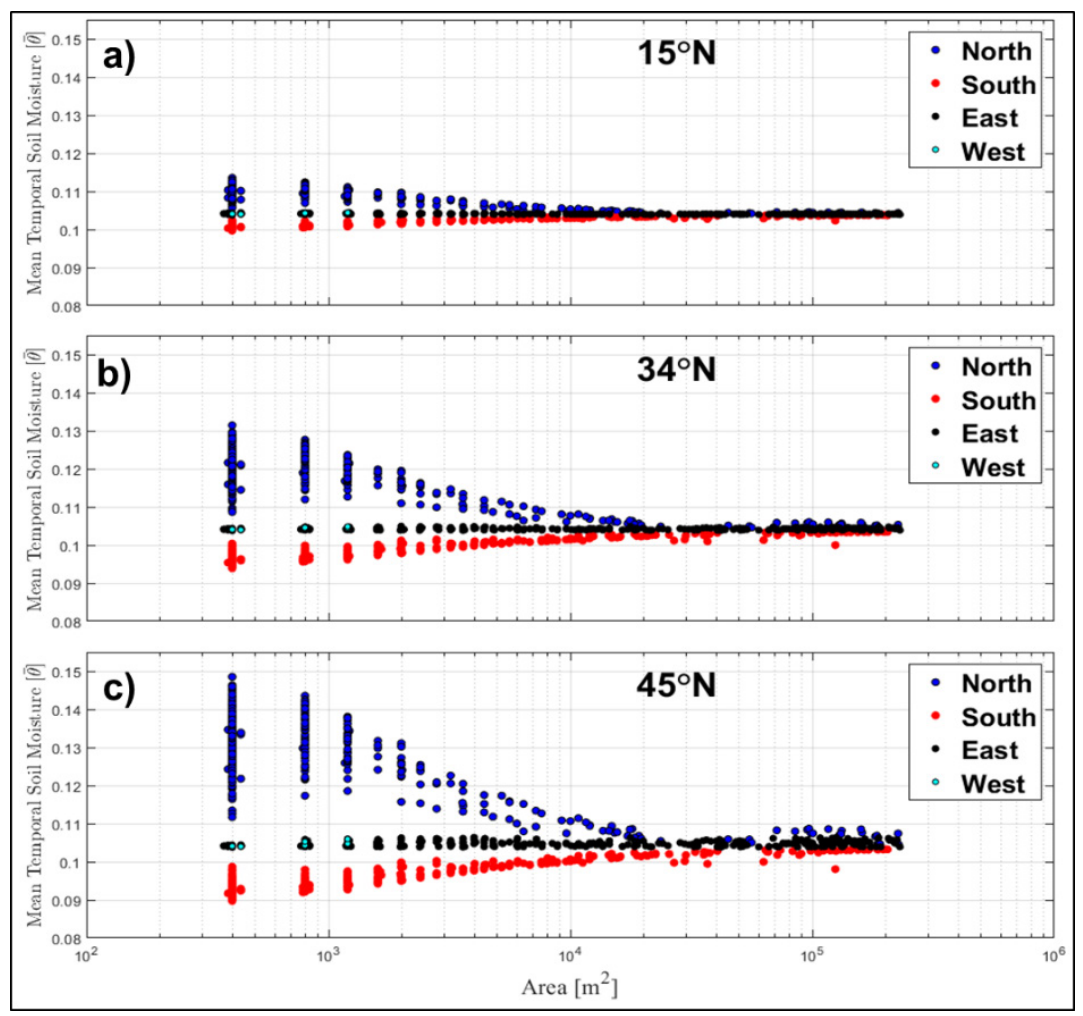

Figure 4. Mean temporal soil moisture $\bar{\theta}$ plotted as a function of drainage area without binning (showing all 1936 pixels) for four different aspects: north-, south-, east-, and west-facing slopes for the entire domain at: (a) $15^{\circ} \mathrm{N}$; (b) $34^{\circ} \mathrm{N}$; and (c) $45^{\circ} \mathrm{N}$. 
The $\bar{\theta}$ range increases as we move from $15^{\circ} \mathrm{N}$ to $45^{\circ} \mathrm{N}$, also the magnitude of soil moisture on the NFS becomes larger than that on the SFS. The $\overline{\boldsymbol{\theta}}$ corresponding to lower drainage area $\left(\sim 400 \mathrm{~m}^{2}\right)$ has a wider range for all the latitudes and decreases towards the higher drainage area. This shows that the role of aspect diminishes towards the higher drainage area. The range of $\overline{\boldsymbol{\theta}}$ at $15^{\circ} \mathrm{N}$ varies between $0.099-0.113$ (Figure 4a) which is lower than $34^{\circ} \mathrm{N}(0.093-0.131$ shown in Figure $4 \mathrm{~b})$ and $45^{\circ} \mathrm{N}(0.089-0.148$ shown in Figure $4 \mathrm{c})$. The soil moisture is higher on the NFS, which can be attributed to decreasing insolation and lower evapotranspiration on the NFS. On the other hand, soil moisture on the SFS is lower than NFS as there is a marginal increase (20\%) in receiving solar radiation on SFS than NFS (McMahon, 1998). The greater amount of solar radiation received on the SFS results in more evapotranspiration than NFS. Higher latitude increases the difference in incoming solar radiation on opposing hillslope aspect (Zou et al., 2007; Yetemen et al., 2015 b); hence, the values vary within a wider range than the case of lower latitude.

\subsection{Exceedance probability of soil moisture at different latitudes}

Figure 5 illustrates the exceedance probability curve of the $\bar{\theta}$ plotted at $15^{\circ} \mathrm{N}, 34^{\circ} \mathrm{N}$, and $45^{\circ} \mathrm{N}$. This figure shows that the probabilities of exceeding the $\bar{\theta}$ of 0.11 are $10 \%, 25 \%$, and $27 \%$ at $15^{\circ} \mathrm{N}, 34^{\circ} \mathrm{N}$, and $45^{\circ} \mathrm{N}$ latitude, respectively. There is a probability of $10 \%$ to have the $\bar{\theta}$ greater than $0.11,0.12$, and 0.14 at $15^{\circ} \mathrm{N}$, $34^{\circ} \mathrm{N}$, and $45^{\circ} \mathrm{N}$ latitude, respectively. It is observed that around $50 \%$ of the total pixels have $\bar{\theta}$ greater than or equal to 0.104 at all three latitudes. However, there exists a probability of only $10 \%$ that $\overline{\boldsymbol{\theta}}$ is less than or equal to $0.1\left(15^{\circ} \mathrm{N}\right), 0.095\left(34^{\circ} \mathrm{N}\right)$, and 0.092 $\left(45^{\circ} \mathrm{N}\right)$. The differences in the pattern of the exceedance probability of $\overline{\boldsymbol{\theta}}$ are observed due to the variation in the amount of insolation at different aspects. As, the east-facing slopes (EFS) and westfacing slopes (WFS) along with the NFS comprises of $\sim 61 \%$ of the total pixels. While $\sim 39 \%$ pixels of the domain falls in the SFS which hold least soil moisture. Also, the sharp change in the exceedance probability for all the latitudes is due to the negligible differences exist in the $\overline{\boldsymbol{\theta}}$ in the east-west facing slopes. Briefly, the main difference between latitudes is mostly the tails, low and high $\overline{\boldsymbol{\theta}}$ values come from SFS and NFS

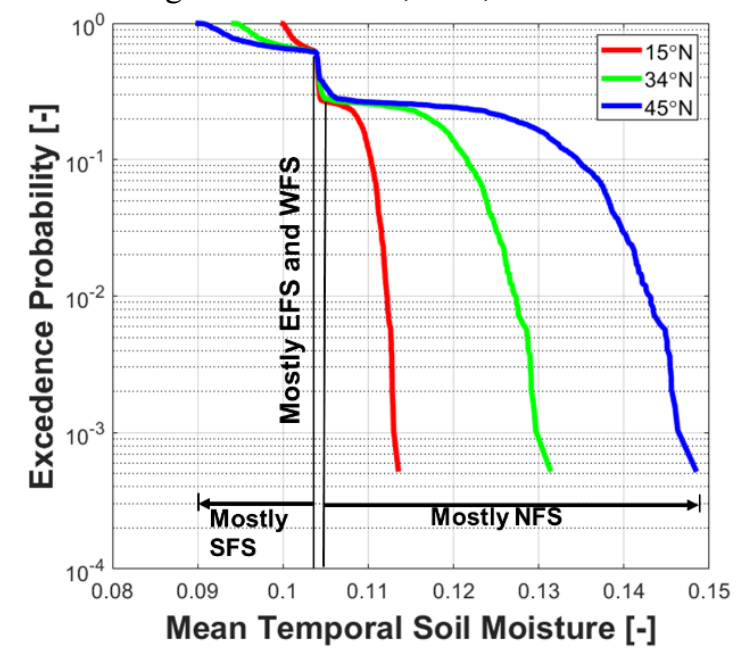

Figure 5. Exceedance probability of mean temporal soil moisture without binning (showing all 1936 pixels) for the entire domain for four different aspects at three different latitudes.

\section{CONCLUSION}

In this study, we used the ecohydrology model BGM that simulates single species vegetation dynamics, using a single bucket with a vertically averaged soil moisture content in the root zone. We performed numerical simulations at $15^{\circ} \mathrm{N}, 34^{\circ} \mathrm{N}$, and $45^{\circ} \mathrm{N}$ to show the influence of latitude and aspect on spatio-temporal variations of soil moisture in the semi-arid ecosystems. The latitudinal pattern of modelled soil moisture is analysed, and distinct variations are seen in the $C V-\langle\theta\rangle$ relationship. The model results show that the higher spatial variability at $45^{\circ} \mathrm{N}$ than $15^{\circ} \mathrm{N}$ is a direct outcome of differences in solar radiation-driven soil moisture; an effect that is magnified at high latitudes. In our results, we found that less insolated NFS support more soil moisture than more insolated SFS. Further, for $\overline{\boldsymbol{\theta}}$ at higher latitude, NFS show higher soil moisture than SFS, and hold a wider range of soil moisture than lower latitude. Negligible differences exist in the $\overline{\boldsymbol{\theta}}$ in the east-west facing slopes for all the latitudes. The modelled soil moisture is higher on steep NFS and decreases with growing drainage areas, while the modelled soil moisture is lower on steep SFS and consistently grows as a function of drainage areas. Also, as we move towards the higher drainage areas, the role of aspect diminishes for all the four aspects at $15^{\circ} \mathrm{N}, 34^{\circ} \mathrm{N}$, and $45^{\circ} \mathrm{N}$ latitudes. Overall, the results show how latitude and aspect-related soil moisture differences play a significant role in the spatial and temporal distribution of soil moisture in semi-arid ecosystems. 
Srivastava et al., Aspect-controlled spatial and temporal soil moisture patterns across three different latitudes

\section{REFERENCES}

Bass, B., Cardenas, M. B., Befus, K. M. (2016). Seasonal Shifts in Soil Moisture throughout a Semiarid Hillslope Ecotone during Drought: A Geoelectrical View. Vadose Zone Journal, 16(2).

Brocca, L., Moramarco, T., Melone, F., Wagner, W., Hasenauer, S., Hahn, S. (2012). Assimilation of surfaceand root-zone ASCAT soil moisture products into rainfall-runoff modelling. IEEE Transactions on Geoscience and Remote Sensing, 50(7). 2542-2555.

Choi, M., Jacobs, J. M., Cosh, M. H. (2007). Scaled spatial variability of soil moisture fields. Geophysical Research Letters, 34(1).

Chen, M., Willgoose, G. R., Saco, P. M. (2014). Spatial prediction of temporal soil moisture dynamics using HYDRUS-1D. Hydrological processes, 28, 171-185.

Famiglietti, J. S., Ryu, D. R., Berg, A. A., Rodell, M. Jackson, T. J. (2008). Field observations of SMV across scales, Water Resources Research, 44, W01423.

Fatichi, S., Katul, G. G., Ivanov, V. Y., Pappas, C., Paschalis, A., Consolo, A., Kim, J., Burlando, P. (2015). Abiotic and biotic controls of soil moisture spatiotemporal variability and the occurrence of hysteresis, Water Resources Research, 51, 3505-3524.

Gutiérrez-Jurado, H. A., E. R. Vivoni, C. Cikoski, J. B. J. Harrison, R. L. Bras, and E. Istanbulluoglu (2013), On the observed ecohydrologic dynamics of a semiarid basin with aspect-delimited ecosystems, Water Resources Research, 49, 8263-8284.

Istanbulluoglu, E., Wang, T. J., Wedin, D. A. (2012). Evaluation of ecohydrologic model parsimony at local and regional scales in a semiarid grassland ecosystem, Ecohydrology, 5(1), 121-142.

Ivanov, V. Y., Fatichi, S., Jenerette, G. D., Espeleta, J. F., Troch, P. A., Huxman, T. E. (2010). Hysteresis of soil moisture spatial heterogeneity and the "homogenizing" effect of vegetation, Water Resources Research, 46, W09521.

Laio, F., Porporato, A., Ridolfi, L., Rodriguez-Iturbe, I. (2001). Plants in water-controlled ecosystems: Active role in hydrologic processes and response to water stress II. Probabilistic soil moisture dynamics, Advances in Water Resources, 24(7). 707-723.

Martinez, C., Hancock, G. R., Kalma, J. D., Wells, T. (2008). Spatio-temporal distribution of near-surface and root zone soil moisture at the catchment scale. Hydrological processes, 22(14). 2699-2714.

McMahon, D. R. (1998). Soil, Landscape, and Vegetation Interactions in Small Semi-Arid Drainage Basin: Sevilleta National Wildlife Refuge, New Mexico, NMTech, Socorro, N. M.

Penna, D., Brocca, L., Borga, M., \& Dalla Fontana, G. (2013). Soil moisture temporal stability at different depths on two alpine hillslopes during wet and dry periods. Journal of Hydrology, 477, 55-71.

Reid, I. (1973). The influence of slope orientation upon the soil moisture regime and its hydrogeomorphological significance. Journal of Hydrology, 19(4), 309-321.

Rossi, M. J., Ares, J. O., Jobbágy, E. G., Vivoni, E. R., Vervoort, R. W., Schreiner-McGraw, A. P., Saco, P. M. (2018). Vegetation and terrain drivers of infiltration depth along a semiarid hillslope. Science of the Total Environment, 644, 1399-1408.

Saco, P. M., Moreno-de las Heras, M. (2013). Ecogeomorphic coevolution of semiarid hillslopes: Emergence of banded and striped vegetation patterns through interaction of biotic and abiotic processes. Water Resources Research, 49(1), 115-126.

Saco, P. M., Moreno-de las Heras, M., Keesstra, S., Baartman, J., Yetemen, O., Rodríguez, J. F. (2018). Vegetation and soil degradation in drylands: nonlinear feedbacks and early warning signals. Current Opinion in Environmental Science \& Health, 5, 67-72.

Western, A. W., Zhou, S. L., Grayson, R. B., McMahon, T. A., Bloschl, G., Wilson, D.J. (2004). Spatial correlation of soil moisture in small catchments and its relationship to dominant spatial hydrological processes. Journal of Hydrology, 286, 113-134.

Yetemen, O., Istanbulluoglu, E., Flores-Cervantes, J.H., Vivoni, E.R., Bras, R.L. (2015a). Ecohydrologic role of solar radiation on landscape evolution, Water Resources Research, 51, 1127-1157.

Yetemen, O., Istanbulluoglu, E., Duvall, A. R. (2015b). Solar radiation as a global driver of hillslope asymmetry: Insights from an ecogeomorphic landscape evolution model. Water Resources Research, 51(12), 9843-9861.

Zhou, X., Istanbulluoglu, E., Vivoni, E. R. (2013). Modelling the ecohydrological role of aspect-controlled radiation on tree-grass-shrub coexistence in a semiarid climate. Water Resources Research, 49(5). 28722895.

Zou, C. B., G. A. Barron-Gafford, and D. D. Breshears (2007), Effects of topography and woody plant canopy cover on near-ground solar radiation: Relevant energy inputs for ecohydrology and hydropedology, Geophysical Research Letters, 34, L24S21. 